\title{
Estágio transdisciplinar: outra formação, outra educação, outro ensino, outra aprendizagem
}

\author{
Lindalva Pessoni Santos* \\ Cláudia do Nascimento ** \\ Marilza Vanessa Rosa Suanno ***
}

\section{Resumo}

Neste artigo, propõe-se apresentar e refletir a proposta de Estágio Curricular Supervisionado do $7^{\circ}$ e $8^{\circ}$ períodos, do Curso de Pedagogia, UEG, Câmpus Inhumas, desenvolvida nos anos iniciais do ensino fundamental na Escola Estadual de Tempo Integral João Lobo Filho em 2013, 2014 e 2015. A Proposta está alicerçada no novo paradigma educativo emergente, baseado na transdisciplinaridade, pensamento complexo e sustentabilidade. Um dos movimentos da Proposta de Estágio é religar sujeito e objeto, conhecimento científico e senso comum, professor e aluno, indivíduo e meio, parte e o todo, o local e o global, entre outros. A visão dicotomizada desses elementos ignora a inteireza humana que, no ato de viver, não parcela e nem hierarquiza as dimensões que a constitui: a física, a social, a cultural, a psíquica, a espiritual, que se converge em uma unidade dinâmica. Contrapondo essa lógica fragmentada e excludente, o que se pretende apresentar neste artigo, é a elaboração e materialização de práticas educativas transdisciplinares desenvolvida no estágio; são três projetos que propõem viabilizar a criação e realização de práticas pedagógicas integradoras vinculadas à dinâmica complexa da vida. A interlocução foi feita com Moraes (1994, 2008, 2014); Morin (1996, 2000); Suanno $(2014,2015)$, entre outros.

Palavras- chave: Estágio transdisciplinar, formação docente, pensamento complexo, paradigma emergente.

Transdisciplinary internship: another formation, another teaching, another learning

* Professora de Atividade de Orientação e Estágio Supervisionado em Docência na Educação Infantil; Professora do Programa de Pós-Graduação Lato Sensu Transdisciplinaridade e Interdisciplinaridade na Educação e Linguagem, Cultura e Ensino (UEG-Câmpus Inhumas); coordenadora da E.E.T.I João Lobo Filho (2011 a 2015) - Email: lindalpessoni@yahoo.com.br

** Graduada em Pedagogia pela Universidade Estadual de Goiás - UEG - Câmpus - Inhumas. Email: claudia_pedagogia2012@hotmail.com

*** Professora da Faculdade de Educação da Universidade Federal de Goiás - UFG. Professora da disciplina Estágio Supervisionado em Docência nos anos iniciais do ensino fundamental - UEG/Câmpus Inhumas (2010- 2015). Email: marilzasuanno@uol.com.br. 


\begin{abstract}
In this article, it is proposed to present the proposal of the Supervised Internship from the $7^{\text {th }}$ and $8^{\text {th }}$ periods, from the Pedagogy Course, UEG, Inhumas Campuses, developed in the early years of the Elementary School in the Full-Time State School João Lobo in 2013, 2014 and 2015. The proposal is grounded in the new emerging educational paradigm, based in the transdisciplinary, complex thinking and sustainability. One of the movements of the Internship Proposal is to rebind subject and object, scientific knowledge and common sense, teacher and pupil, individual and means, part and all, the local and the global, and so on. The dichotomized vision of these elements ignores the human integrity that, in the action of living, doesn't parcel its constitutive dimensions: the physical, the social, the cultural, the psychic, the spiritual, that converts itself in a dynamic unity. Opposed to this fragmented and exclusionary logic, what is intended to present in this article, is the elaboration and the materialization of the transdisciplinary educational practices developed in the internship; there are three projects that propose to enable the creation and the realisation of the integrated pedagogic practices connected to the complex dynamic of life. The interlocution has been made with Moraes $(1994,2008,2014)$; Morin (1996, 2000); Suanno (2014, 2015), and so on.
\end{abstract}

Keywords: Internship transdisiplinary, teaching training, complex thinking, emerging paradigm.

Introdução

O Estágio Curricular Supervisionado é um componente curricular da formação acadêmica tendo caráter teórico, reflexivo, criativo, um procedimento de ensino com pesquisa elaborador de práxis docente, de construção de conhecimentos da profissão docente a partir de uma determinada realidade da educação escolar. O Estágio Curricular Supervisionado não se constituindo como trabalho profissional, sendo uma atividade supervisionada, com fins formativo didático-pedagógico, firmado por meio de parceria estabelecida mediante instrumento jurídico entre a Universidade Estadual de Goiás - UEG e a Escola-Campo de Estágio, conforme determina a legislação vigente.

Os fundamentos teórico-práticos da perspectiva adotada, no estágio, nas series iniciais, do Curso de Pedagogia, da UEG, Câmpus Inhumas estão diretamente ligados à ruptura com o paradigma educacional vigente num movimento que demarca a passagem de uma educação transmissora em uma educação transformadora fundamentada em princípios como o diálogo, a valorização e respeito ao outro e aos seus diferentes saberes. Nesse sentido, a preocupação é definir ações que desenvolvam competências que qualifiquem não somente para vida profissional, mas para vida em que a tríade natureza/sociedade/indivíduo seja entendida como um todo integrado.

Esse processo de transição paradigmática pode ser percebido por meio das rupturas empreendidas nos projetos de estágio que apontam para a proposição de uma 
nova dinâmica educacional fundamentada nos princípios da transdisciplinaridade, do pensamento complexo, do paradigma emergente.

O estágio curricular, na formação de professores, no Curso de Pedagogia, desenvolve por meio da apreensão, problematização e pesquisa sobre a realidade escolar, os processos de ensino, a aprendizagem dos alunos (as), as especificidades da organização e gestão da escola e fundamentalmente possibilita ao estagiário (a) se perceber, se experimentar, se desafiar como professor (a) em um campo de estágio. Sendo este um momento na formação de professores que favorece a relação entre teoria e prática e visa contribuir para a construção de conhecimentos, compromissos, sensibilidades, valores, atitudes e habilidades inerentes à profissão docente, à identidade docente, à profissionalidade e à função social dos espaços educativos (SUANNO, 2015).

Desse modo, este artigo buscou apresentar e refletir acerca da proposta de estágio nas séries iniciais do ensino fundamental experenciada pelos acadêmicos do $7^{\circ} \mathrm{e}$ $8^{\circ}$ períodos, do Curso de Pedagogia, da UEG, Câmpus Inhumas em 2013, 2014, 2015.

A par disso, este estudo foi organizado em duas partes. Primeiro apresentou-se uma reflexão acerca da proposta de Estágio Supervisionado em docência nas series iniciais do ensino fundamental, da UEG, Câmpus Inhumas como um lócus de mudança paradigmática; a segunda parte é descrito e analisado os projetos desenvolvidos em 2013, 2014, 2015 no/pelo Estágio Supervisionado na Escola Estadual de Tempo Integral João Lobo Filho.

Princípios, fundamentos e organização do Estágio Curricular Supervisionado em Docência nos anos iniciais do Ensino Fundamental - Curso de Pedagogia, UEG/ Câmpus Inhumas

O Estágio Curricular Supervisionado em Docência nos anos iniciais do Ensino Fundamental lecionado em dois semestres letivos, no $7^{\circ}$ e $8^{\circ}$ períodos do curso de Pedagogia na UEG/Câmpus Inhumas, tem carga horária de 100 (cem) horas para cada uma das duas disciplinas. E a disciplina Atividades de Orientação em Docência nos anos iniciais do Ensino Fundamental é uma disciplina complementar e conjugada ao estágio tendo por objetivo o estudo da fundamentação teórica, o planejamento do projeto de ensino com pesquisa e a orientação das atividades e reflexões desenvolvidas no estágio curricular supervisionado.

O Estágio Curricular Supervisionado em Docência nos anos iniciais do Ensino Fundamental, fundamenta-se e dialoga com: a) a Epistemologia da Complexidade e o pensamento complexo (MORIN, 1996; 2000; 2007; 2008; 2009;); b) o paradigma 
educacional emergente (MORAES, 1997, 2008; 2014); c) a perspectiva de auto-hetero -ecoformação (PINEAU, 2006); d) os processos de ensino e de aprendizagem em perspectiva interdisciplinar (FAZENDA, 1979; JAPIASSU, 1974); e) os processos de ensino e de aprendizagem em perspectiva transdisciplinar (NICOLESCU, 1999; MORAES, 2015; SUANNO, 2015d, 2015e), organizados e sistematizados por meio de Projetos de Trabalho Transdisciplinares (HERNÀNDEZ e VENTURA, 1998).

Conforme Suanno (2015e) o estágio na formação de professores é uma disciplina que fundamentalmente possibilita ao estagiário (a) perceber-se e vivenciar o trabalho docente, a relação com a profissão, com o conhecimento didático, a relação com a equipe escolar e com a aprendizagem dos alunos(as) da Escola-Campo. O estágio visa contribuir para a construção de conhecimentos, valores, atitudes e perspectivas sobre o trabalho docente, a identidade docente e a profissionalidade.

O estágio curricular tem a intencionalidade de promover práxis complexa e transdisciplinar (SUANNO, 2013, 2015d, 2015e), por meio da construção de um modo de pensar problematizado, relacional, que busca religar conhecimentos em perspectiva multidimensional, multirreferencial e autorreferencial, com vistas a construir ações, relações e mediações pedagógicas com potencial transformador de si mesmo, do social e da relação homem-natureza-sociedade.

Tal concepção de estágio se vincula a valorização da pesquisa, da problematização da realidade, da transdisciplinaridade e do papel ativo, dinâmico e auto-organizador dos sujeitos em processos formativos. O Estágio Curricular como uma atividade teórica instrumentalizadora da práxis complexa e transdisciplinar valoriza a razão sensível, a religação entre saberes científicos e saberes das tradições via Pensamento Complexo (MORIN, 2011) e transdisciplinaridade (MORAES, 2015; SUANNO, 2015d).

A docência emergente (SUANNO, 2015e) se constrói a partir da relação entre teoria, prática, ação transformadora e reintrodução do sujeito cognoscente na produção do conhecimento (princípio operador do pensamento complexo). A partir deste princípio compreende-se o conhecimento como fruto de uma construção relacional, dinâmica, interativa e recursiva entre sujeito e objeto, envolto em níveis de realidade, níveis de percepção e níveis de consciência. Nesse sentido, o conhecimento se constrói na interatividade dinâmica e no acoplamento estrutural entre sujeito e objeto e estas são "interações intrassubjetivas e intersubjetivas" (MORAES, 2008, p. 124). A docência emergente, na perspectiva complexa e transdisciplinar, pode ser impulsionada por meio as oportunidades criadas e construídas no estágio curricular supervisionado, pois: 


\begin{abstract}
O estágio por desenvolver-se em situações concretas e contextualizadas favorece a articulação entre saberes teóricos, saberes docentes, saberes da ação docente, práticas institucionais, políticas públicas, práticas da comunidade escolar e contextos históricos, sociais, culturais, organizacionais e profissionais. De tal modo, favorece a reorganização e a ressignificação do trabalho docente via ações transformadoras da realidade e dos sujeitos que reorganizam a si mesmo, seus conhecimentos, suas percepções sobre a profissão, sua atuação no campo de estágio, conhecendo a si mesmo como profissional, comprometendo-se com a profissão e a identidade profissional e em permanente exercício da crítica das condições materiais nos campos de estágio (SUANNO, 2015d, p. 18).
\end{abstract}

O estágio em docência nos anos iniciais do ensino fundamental, no Curso de Pedagogia, da UEG Câmpus Inhumas, assume a perspectiva inter/transdisciplinar e tem a intencionalidade de romper com a fragmentação do conhecimento, com a linearidade do pensamento, a disciplinaridade na organização do conhecimento e na gestão do processo de ensino. E tem se proposto a estudar e pesquisar problemas reais, por meio da seleção de metatemas pertinentes e fundamentais na formação humana no século XXI, o que demanda religar conhecimentos e saberes a fim de pensar complexo.

A transdisciplinaridade transcende as fronteiras do conhecimento disciplinar ampliando a formação humana, por isso o estágio na UEG Câmpus Inhumas aposta na perspectiva transdisciplinar. Para Nicolescu (1999, p. 53):

a transdisciplinaridade, como o prefixo trans indica, diz respeito àquilo que está ao mesmo tempo entre as disciplinas, através das diferentes disciplinas e mais além de qualquer disciplina. Seu objetivo é a compreensão do mundo presente, para o qual um dos imperativos é a unidade do conhecimento.

Assim, a transdisciplinaridade busca romper com as fronteiras disciplinares com o intuito de superar a fragmentação do conhecimento e construir uma compreensão que organize hologramática e sistemicamente o objeto de investigação ou de estudo. Para tal, promove migração e articulação de conceitos e metodologias de diferentes áreas do conhecimento, uma vez que "a transdisciplinaridade se interessa pela dinâmica gerada pela ação de vários níveis de realidade ao mesmo tempo" (NICOLESCU, 1999, p. 54).

Conforme Nicolescu (1999), esse princípio epistemológico materializa-se a partir da relação entre os níveis de realidade, a lógica do "terceiro incluído" e a com- 
plexidade. Neste sentido, cada nível de realidade, correspondente, está associado a um tipo de percepção do pesquisador.

A transdisciplinaridade, inspirada no pensamento complexo, propõe um modo de conhecer e produzir conhecimento que necessita de uma pulsão religadora de conhecimentos, saberes e culturas, em perspectiva multirreferencial, multidimensional e autorreferencial. A transdisciplinaridade é uma via de transformação da organização social, de metamorfose, como diria Morin (2011), uma via de transformação da relação entre homem, ciência, cultura e natureza; uma via de autotransformação orientada para o conhecimento e para a criação de nova arte de viver e um novo sentido para a vida, pautada na Epistemologia da Complexidade, na qual a economia deve estar a serviço do ser humano e não o inverso (SUANNO, 2015e).

Nesse sentido, a transdisciplinaridade deve ser percebida como um princípio epistemológico e metodológico que visa à construção de outros níveis de percepção, outros níveis de consciência, que possibilitem aos homens a construção de novas concepções, atitudes e propostas metodológicas criativas e inovadoras rumo à construção de conhecimentos transdisciplinares e de educação transdisciplinar (SUANNO, 2015d, 2015e).

O Estágio do Curso de Pedagogia propõe e tem trabalhado com a interdisciplinaridade e com transdisciplinaridade a fim de pensar complexo e ampliar a formação do pedagogo; oportuniza aos estagiários(as) o estudo das teorias e dos saberes didáticos contemporâneos e a partir da teoria instrumentaliza o pensamento e a ação na elaboração de processo educativos criativos, inovadores e integradores, capazes de ecologizar saberes em Projetos de Trabalho complexos e transdisciplinares.

A UEG e o Câmpus Inhumas: construindo marcos que indicam que é possível exercer uma docência transdisciplinar

A universidade tem desenvolvido ações, projetos, práticas que apontam uma prática testemunhal de um dizer inovador e criativo que indica uma transição paradigmática? É possível nas últimas décadas encontrar apontamentos, discussões e pesquisas sobre o paradigma moderno e suas implicações no modo de pensar e fazer educação na universidade e no ensino superior, bem como captar um movimento indicativo de transição paradigmática, não somente a nível conceitual, mas epistemometodológico, proveniente, especialmente, da análise de ações consideradas criativas e inovadoras no campo da docência?

A Universidade Estadual de Goiás, por exemplo, é uma instituição recente- 
mente estruturada e é organizada como uma universidade multicampi. O Câmpus Inhumas foi criado em 1999, conta com dois Cursos de licenciatura presencial, no turno noturno: Pedagogia e Letras; treze Cursos de Extensão; e, em períodos intercalados e às vezes concomitantes oferece Cursos de Especialização. Atualmente, conta com a II turma de Especialização em Transdisciplinaridade e Interdisciplinaridade na Educação (2015/2016), tendo concluído a primeira em dezembro de 2015, uma turma de Especialização em Linguagem, Cultura e Ensino (2016/2017).

Apesar do Câmpus de Inhumas ser um espaço acadêmico com pouquíssima idade, ele tem feito um movimento em busca de promover uma ruptura com o paradigma dominante no campo da formação docente por meio de discussões, encontros, eventos, Curso de Extensão e Especialização, publicações, ações e projetos imbuídos dos princípios e fundamentos do paradigma emergente, do pensamento complexo, da interdisciplinaridade e transdisciplinaridade.

Este artigo pautou-se em ações afirmativas em decorrência das experiências significativas, articuladas e vivenciadas por professores, acadêmicos e comunidade que estão tendo a oportunidade de experimentar a tão questionada relação teoria e prática. Neste caso, a perspectiva real de uma docência subsidiada pelos princípios e fundamentos do pensamento complexo, da interdisciplinaridade e transdisciplinaridade.

A primeira experiência empreendida no Câmpus Inhumas - UEG, a partir dos princípios e fundamentos do pensamento complexo, da interdisciplinaridade e transdisciplinaridade, foi em 2013, com uma turma do $8^{\circ}$ Período, do Curso de Pedagogia, no Estágio Supervisionado em Docência nas Séries Iniciais, sob a orientação da professora Marilza Vanessa Rosa Suanno. A proposta de estágio foi desenvolvida na Escola Estadual de Tempo Integral João Lobo Filho nas turmas $3^{\circ} \mathrm{e} 5^{\circ}$ ano do ensino fundamental. De acordo com a professora, a proposta de estágio, proporcionou uma oportunidade singular para os acadêmicos do Curso de Pedagogia e aos alunos do campo, uma vez que o objetivo foi:

[...] promover práxis complexa e transdisciplinar em torno do metatema 'Cooperação internacional pelas águas'. No intuito de construir um modo de pensar problematizado, relacional, que busca religar conhecimentos em perspectiva interdisciplinar e transdisciplinar (multidimensional, multirrefrencial, autorrerencial), construindo pensamentos, relações e mediações pedagógicas com potencial transformador de si mesmo, do social e da relação homem- natureza-sociedade (SUANNO, 2014, p. 205). 
A primeira experiência de docência transdisciplinar emergente desenvolvida no/pelo estágio foi uma oportunidade para os acadêmicos e para o campo de estágio (alunos, professores, grupo gestor, pais) de experimentar um processo de ensino e de aprendizagem que transcendesse as gaiolas disciplinares. Partindo de uma questão mobilizadora/problematizadora, esta ação proporcionou o pensar complexo e transdisciplinar, utilizando metodologias ativas, dialógicas, interativas em que o aluno foi coautor das propostas desenvolvidas a partir das concepções de Projeto de trabalho (HERNÁNDEZ, 1998 apud SUANNO, 2014).

Desta forma:

Ao longo do projeto de trabalho as aulas foram participativas, dialógicas e desenvolvidas por meio de metodologias ativas; situações-problemas; problematização da temática; pesquisa; interpretação (de documentários, animes, fotos, infográficos, gráficos, gráficos, mapas, letras de músicas, histórias em quadrinhos, charges, lendas, textos jornalísticos, narrativas, letras de músicas, histórias em quadrinhos, charges, lendas, textos jornalísticos, narrativas, livros literários); produção textual; teatro de fantoches; dramatizações; escuta musical e jogos interpretativos. (SUANNO, 2014, p. 208).

Para coroar esta primeira experiência de docência transdisciplinar, com o incentivo, apoio e organização da professora Marilza Suanno (2013) publicou-se o livro: Projetos, práticas e estágio nos anos iniciais do ensino fundamental- Ano Internacional de Cooperação pela água que reunia Projetos, práticas pedagógicas, poemas, desenhos, relatos de experiências das pessoas que estiveram direta e indiretamente envolvidas nas atividades do estágio (grupo gestor, alunos, professores, pessoas da comunidade, além dos relatos dos grupos de Estágio). Convém ressaltar que por meio desses relatos foi possível perceber a perplexidade dos alunos estagiários diante da proposta da referida professora e ao mesmo tempo a satisfação em vivenciar a possibilidade inovadora de um ensino transdisciplinar.

Tais relatos também foram apresentados no II Seminário de Estágio e IV Mostra de Curtas na Educação Infantil- Este Evento é organizado pelas professoras de Estágio da UEG/ Câmpus Inhumas e marca a culminância dos Estágios Supervisionados do Curso de Pedagogia em Docência na Educação Infantil e nas Series Iniciais dos $5^{\circ}$ e $6^{\circ}$ e $7^{\circ}$ e $8^{\circ}$ períodos respectivamente.

Em 2014, a perspectiva da docência transdisciplinar se ampliou muito no Câmpus Inhumas. Inicialmente com a elaboração e desenvolvimento da II Proposta de 
Estagio Transdisciplinar nas séries iniciais do ensino fundamental, desta vez em duas escolas, com o envolvimento de todos os professores dos $7^{\circ} \mathrm{e} 8^{\circ}$ períodos do Curso de Pedagogia.

\begin{abstract}
Em síntese, nas diferentes disciplinas, os acadêmicos do $4^{\circ}$ ano de Pedagogia da UEG/Inhumas tiveram a oportunidade de pensar, discutir e refletir sobre a temática "Cidades sustentáveis: por uma Inhumas Sustentável", percebendo as interfaces, as diversas realizações e as contradições que a compõem. E a partir desta oportunidade de pensar complexo e transdisciplinar sobre a temática, na disciplina de Estágio, construiu o planejamento e o desenvolvimento dos projetos de trabalho, desenvolvido nas escolas com crianças dos anos iniciais do ensino fundamental. O trabalho de estágio foi organizado e pensado, articulando-se com as outras disciplinas do Curso de Pedagogia. Este projeto se desenvolveu em duas escolas da cidade de Inhumas, sendo elas: Escola Estadual de Tempo Integral João Lobo Filho e a Escola Municipal Professora Cleide Campos (SUANNO et al, 2015, p. 115-116).
\end{abstract}

O Projeto de Estágio: Cidades sustentáveis: por uma Inhumas Sustentável foi desenvolvido a partir de diferentes frentes de trabalho empreendida pela orientadora do estágio, professora Marilza Vanessa Rosa Suanno e os grupos de Estágio na Escola Estadual João Lobo Filho; uma das primeira ações foi promover formação continuada aos professores da escola e reunião com os pais e comunidade para expor a proposta do projeto; num segundo momento o trabalho se estendeu para os alunos com o desenvolvimento efetivo do projeto a partir de pesquisas sobre problemas que a cidade de Inhumas tem e o levantamento de sugestões de soluções - as soluções poderiam ser inspiradas nas cidades sustentáveis estudadas; pesquisas em: jornais, internet, facebook, documentos da prefeitura local, notícias e fotos sobre ações sustentáveis já adotadas pela cidade de Inhumas; elaboração de carta aberta à comunidade inhumense; elaboração de textos coletivos com a síntese do que aprenderam sobre: $\mathrm{O}$ que são cidades sustentáveis? Quais as cidades sustentáveis que conhecem? O que cada uma das cidades estudadas tem realizado de sustentável? Fotos de ações de cidades sustentáveis; criação de facebook: Inhumas sustentável; pesquisa com os pais sobre o que eles compreendem sobre cidade sustentável; investigação sobre o Projeto Girassol - iniciativa de uma agente de saúde com a participação da comunidade inhumense que limpa e torna produtivo ou decorativo com o plantio de girassóis em lotes baldios em toda a cidade; potencialização das ações sustentáveis já desenvolvidas pela escola: horta escolar comunitária; decoração criativa e sustentável da escola (reaproveitamento de pneus usados, prática do plantio, garrafa pet); Projeto sabão caseiro (reaproveitamento 
de óleo usado, produção de detergente e desinfetante); implantação da coleta seletiva na escola (papel, plástico, alumínio, vidro e outros).

O estreitamento da parceria da UEG Câmpus Inhumas com a escola campo - Escola Estadual de Tempo Integral João Filho - em 2014, por meio do Estágio, fez com que seus projetos fossem ressignificados, ampliados e alguns certificados como transdisciplinares, criativos e inovadores. Esse processo resultou na apresentação do trabalho: Um projeto, uma feira e muita aprendizagem... (SANTOS, 2014) no I Seminário RIEC - Rede Internacional de Escolas Criativas - Goiânia; além do convite para apresentar o trabalho, a escola foi desafiada a criar um símbolo para representar o Evento, o resultado foi a confecção de uma toalha de mesa feita pelo alunos onde eles registraram por meio de desenhos, frases, poemas o que eles mais apreciavam na escola. A toalha foi decorada com flores de fuxico que eram confeccionadas na oficina de artes visuais. Esta não se tornou apenas o símbolo do I Seminário do RIEC, como também VI INCREA - Fórum Internacional de Inovação e Criatividade - Barcelona no mesmo ano; neste Evento foi apresentado o trabalho da Escola: Essa é uma história de uma feira de ciências (SANTOS; SUANNO, 2014).

Para ampliar e ilustrar tal proposta sobre cidades sustentáveis organizou-se o $I$ Fórum Internacional sobre Cidades Sustentáveis, Educação e Tecnologias realizado pela UEG, em parceria com a Rede Internacional de Escolas Criativas - RIEC; o Curso de Pedagogia da UEG/Câmpus Inhumas; o Mestrado em Ambiente e Sociedade da UEG/ Câmpus Morrinhos e o Mestrado em Educação, Linguagens e Tecnologias da UEG/ Câmpus UnUCSEH. A Conferência de abertura foi proferida pelo Prof.Dr. Francisco Ramon Garrote Jurado, da Universidade de Boras/Suécia que veio com o propósito de relatar a experiência e os traços culturais, políticos e institucionais da cidade e da Universidade de Boras. Boras é uma das cidades mais sustentáveis do planeta; este título é resultados de ações coordenadas entre sociedade, universidade, empresas, políticas publicas e organizações que visam a qualidade de vida e o desenvolvimento sustentável da cidade (SUANNO et al, 2015).

Neste evento foi apresentado um pôster e uma mesa redonda com os professores do curso de Pedagogia e professores da Escola-campo João Lobo Filho que relataram as primeiras conquistas advindas com o Estágio transdisciplinar na escola; a mesa tinha como tema de discussão: "Cidades sustentáveis: reflexões e proposições do projeto inter/transdisciplinar do Curso de Pedagogia da UEG/Inhumas"; Esta proposta de trabalho integrada entre as disciplinas do $7^{\circ}$ e $8^{\circ}$ período resultou na publicação de um artigo: (SUANNO et al, 2014) Cidades sustentáveis e escolas sustentáveis: projeto inter/transdisciplinar, na Revista DESAFIOS, da UFT. 
Todo esse trabalho promovido pelo estágio foi sistematizado ao final do ano com a montagem de cinco murais que foram apreciados na VI Mostra Pedagógica e Cultural da Escola pelos professores, alunos, pais, comunidade, autoridades locais, contou também com a presença da professora orientadora de estágio e seus estagiários que expuseram ao público a importância do trabalho desenvolvido junto aquela comunidade. Este trabalho também foi apresentado no III Seminário de Estágio e V Mostra de Curtas na Educação Infantil, da UEG, Câmpus Inhumas.

Em 2015 a proposta de docência transdisciplinar já não causava tanto espanto, uma vez que os acadêmicos, professores e comunidade já conheciam por meio dos eventos realizados pelo Câmpus Inhumas. Neste ano, o metatema da III Proposta de Estágio Transdisciplinar foi Escola Sustentável e práxis emergente; as questões deste projeto giraram em torno do que é sustentabilidade? Quem pratica sustentabilidade? Por que praticar sustentabilidade? Como praticar sustentabilidade? O que é desenvolvimento sustentável? O que é educação e sustentabilidade?

$\mathrm{O}$ intuito do projeto era ampliar o pensar complexo e transdisciplinar sobre escolas sustentáveis e práticas sustentáveis, questões iniciadas nos projetos de estágio anteriores. Foram traçados como objetivos compreender de forma multidimensional, multirreferencial e autorreferencial o conceito de sustentabilidade para refletir novas práticas sustentáveis e perceber que a humanidade criou um novo estilo de vida que gira em torno do consumismo e que precisa ser repensado; implantar práticas sustentáveis na escola para que se possam ser aproveitadas em casa, desenvolver atitudes de respeito ao próximo e ao planeta, incentivar a educação ambiental, promover discussões sobre o consumo consciente, conscientizar sobre a importância de desenvolver práticas sustentáveis buscando minimizar os impactos das mudanças climáticas e assim melhorar a qualidade de vida, dentre outros.

A proposta de Estágio para o ano de 2015 apresentou-se como possibilidade de sensibilizar alunos, professores e comunidade a pensar complexo e refletir sobre questões emergentes. Outro movimento foi apresentar aos alunos e professores da escola campo, ações sustentáveis como: gotejamento, compostagem, incrementação da coleta seletiva e reaproveitamento de resíduos; práticas estas que se iniciariam na escola e se estenderiam à comunidade.

Neste ano ocorreu em Goiânia, no Centro de Ensino e Pesquisa Aplicada à Educação - CEPAE, da Universidade Federal de Goiás - UFG, o VII INCREA e o II RIEC que contou com os alunos e professores da Escola E.E.T.I. João Lobo Filho que foram socializar as experiências vivenciadas na escola a partir das ações empreendidas pelo estágio transdisciplinar. O Evento contou também com os professores e alunos 
do Curso de Pedagogia, alunos da Pós Transdisciplinaridade e interdisciplinaridade na educação, da UEG, Câmpus Inhumas. Os eventos simultâneos contaram com a apresentação de 140 trabalhos de professores e alunos e diferentes instituições educativas; houve a participação de aproximadamente 700 pessoas.

Em virtude da divulgação do estágio transdisciplinar, dos projetos e ações sustentáveis desenvolvidos pela Escola Estadual João Lobo Filho em importantes Eventos, como citados anteriormente, a escola recebeu convite para participar de um outro importantíssimo Evento na capital Goiana: Congresso Pensar XXI, promovido pelo jornal O popular, o evento discutiu neste ano a temática: Direito e Qualidade na Educação. O Tema apresentado pela escola foi: Escola sustentável: projetos com metatemas complexos e novas aprendizagens.

Uma escola que objetiva ser sustentável, em sentido amplo, deve proporcionar experiências que contribuam para o crescimento individual e social do aluno. Ela deve buscar a formação de um aluno que tenha consciência de seu papel enquanto ator social, que de posse do conhecimento, tem possibilidade de compreender e interferir nos rumos da história. O trabalho por projetos com metatemas é um dos caminhos que a escola pode escolher para ampliar a compreensão e o pensar complexo dos alunos, pois busca religar o que está separado numa perspectiva interdisciplinar/transdisciplinar que visa à transformação da escola e da sociedade. Trabalhar por projetos com metatemas contribui para a abertura de diálogos e atitudes que colaboram para o estabelecimento de conexões e relações entre os conteúdos escolares e a vida, além de proporcionar o desenvolvimento da autonomia do educando, o conhecimento de si, do outro e do mundo.

É de fundamental importância que a escola fomente a capacidade do aluno de compreender a realidade e transformá-la. Nessa perspectiva, os professores devem possibilitar aos educandos a construção de novos conceitos e atitudes que os tornem críticos e reflexivos diante da realidade na qual estão inseridos. Para isso, o professor requer uma sensibilidade aguçada para perceber as necessidades, os interesses e especificidades dos educandos, para proporcionar uma prática educativa investigativa e exploratória como meio para (re)significar as experiências vividas, viabilizando a efetivação da aprendizagem. $\mathrm{O}$ trabalho por projetos com metatemas exige mudanças conceituais e organizacionais no processo ensino aprendizagem; uma questão importante para o desenvolvimento desse trabalho é o envolvimento e apoio dos pais e comunidade em geral.

A partir dessas perspectivas, a escola apresentou, no Congresso Pensar XXI, algumas experiências sustentáveis - ações e projetos desenvolvidos pela escola - , 
bem como relatou a parceria com a Universidade Estadual de Goiás - UEG - Câmpus Inhumas e os avanços alcançados em seu processo ensino aprendizagem por meio do desenvolvimento dos projetos de estágio com metatemas complexos como: "Água: fonte da vida", "Cidade sustentável, por uma Inhumas sustentável” e "Escola sustentável e práxis emergente."

Em 2015, também alguns dos trabalhos propostos e desenvolvidos no/pelo Estágio transdisciplinar foram publicados em dois importantes livros que apresentam projetos criativos: (SANTOS; SUANNO; 2015) e relatos de experiência fundamentados na teoria da complexidade, interdisciplinaridade e transdisciplinaridade (SUANNO et al, 2015).

Todo esse processo também foi apresentado no IV Seminário de Estágio e VI Mostra de Curtas na Educação Infantil do Curso de Pedagogia, UEG, Câmpus Inhumas que contou com a participação de professores e alunos da Escola João Lobo Filho que deram depoimentos sobre a perspectiva vivenciada por eles com o estágio transdisciplinar.

Esse movimento promovido pela UEG Câmpus Inhumas vai ao encontro do pensamento de Almeida (2014) que afirma sobre a possibilidade como um devir, um processo, nem pronto, nem acabado, mas construído fora do território racional que acreditamos ser o único possível.

A questão desafiadora ao trabalhar o Estágio foi organizar uma proposta que servisse de parâmetro para análise de projetos de trabalho transdisciplinares e identificar o que os caracterizam como tal quanto ao como fazer diferente no campo das práticas educativas fora do que se conhece do paradigma dominante.

O propósito do Estágio transdisciplinar é sensibilizar os estagiários, criar um ambiente instigador, propício para a construção de conhecimentos e princípios que ressignifique o sentido de ensinar e aprender no mundo atual. Sobre tais questões, Moraes afirma que:

[...] esta nova maneira de pensar e compreender a realidade requer por sua vez, estratégias metodológicas abertas ao imprevisto, ao inesperado, às emergências, às superações das dicotomias e polaridades existentes. Exigem estratégias flexíveis e multidimensionais para compreensão dos movimentos, para o desenvolvimento de estratégias inovadoras e criativas, capazes de descrever e abarcar o comportamento das unidades complexas. O importante é não esquecer que qualquer objeto jamais pode ser aprisionado por uma única explicação da realidade e o mundo jamais poderá ser enclausurado em um único discurso ou nível da realidade (MORAES, 2014, p. 32). 
Os estagiários sentiram-se implicados e motivados na perspectiva de elaborar estratégias que propiciassem a apropriação do conhecimento em um cenário em que o rigor cientifico não aplacasse os sentimentos e a criatividade. A estruturação dos projetos se fizeram a partir de multirreferencias e muldimensões. A proposta na verdade se fundamentava,

[...] em uma transcendência que sinaliza que já é tempo de maior liberdade do espírito humano, tempo em que nenhuma racionalidade cientifica será capaz de aprisionar a emoção, o sentimento e a criatividade do ser humano em nome de uma objetividade que conspira contra a sua própria inteireza (MORAES, 2004, p. 23).

A maioria dos grupos, após as orientações, delineou com muita autonomia as estratégias que utilizariam para desenvolver os projetos de estágio. As propostas traziam em si as diferentes dimensões da vida e as diferentes dimensões constitutivas do ser humano: razão e emoção, objetividade e subjetividade, conhecimento científico e senso comum, conhecimento local e global, entre outros. A perspectiva em que se busca estabelecer parâmetros de uma efetiva prática educativa fundamentada na transdisciplinaridade, pensamento complexo, paradigma emergente.

Se traduzirmos a vida como consequência exclusiva de uma dinâmica linear fica difícil entender a emergência da consciência, da intuição, a sinergia, a criatividade, o papel das emoções e dos sentimentos na produção do conhecimento e no desenvolvimento da aprendizagem [...] (MORAES, 2004, p. 29).

As concepções e práticas desenvolvidas pelo estágio transdisciplinar energizaram professores da escola-campo, pais e comunidade; um dos objetivos do estágio transdisciplinar era sensibilizar para a necessidade de outro modelo de formação docente, de um outro currículo, de uma outra didática. De acordo com Navarra (2012, p. 84) temos que ensinar o conhecimento científico que está em toda parte, ensinar o desejo de aprender, mas "além disso, temos que transmitir valores como responsabilidade, compromisso, solidariedade em uma cidadania global, a prática cotidiana no esforço do estudo e do trabalho".

A perspectiva adotada pelo estágio transdisciplinar era fugir da linearidade, da memorização e repetição de conteúdos sem sentido e possibilitar novas 
relações e conexões elaboradas pelos alunos; os conhecimentos deveriam ser ressignificadas pelos alunos. "As concepções existentes dentro de cada um de nós se revelam também em nossa maneira de conhecer, de aprender e de educar. [...]" (MORAES, 2004, p. 23).

Os projetos deveriam se desenvolver em um clima de cumplicidade e corresponsabilidade para as aprendizagens coletivas, havia muitos questionamentos como forma de rever conhecimentos, posturas, atitudes, sentimentos, ações e reações frente às questões culturais, sociais, econômicas e políticas locais e globais para elaboração de saídas criativas e inovadoras.

Como educadores, temos que pensar seriamente nestas questões se pretendemos educar visando à inteireza humana, onde pensamentos, emoções, intuições e sentimentos estejam em constate diálogo em prol da evolução da consciência humana. Portanto, é necessário que busquemos novas teorias, novas referências que explicitem, como maior clareza, as questões epistemológicas imbricadas no ato de educar (MORAES; TORRE, 2004, p. 55).

Tantos conhecimentos ressignificados e a emergência de novas possibilidades no campo educativo foram capazes de "[...] reencantar educando e educador em um processo compartilhado de construção da aprendizagem, tanto do discente como do docente" (MORAES; TORRE, 2004, p.7).

O estágio transdisciplinar, da UEG, Câmpus Inhumas, contribuiu para a formação de pessoas semeadoras e polinizadoras de uma educação que compartilha conhecimento sem desconsiderar as emoções, os sentimentos, a responsabilidade consigo, com outro e com o planeta como um todo; uma educação integrada, fruto da conjunção de múltiplas linguagens. Essa é a perspectiva dos projetos de estágio, "[...] o desenvolvimento de estratégias didáticas que privilegiem diferentes tipos de linguagem, que estimulem desafios, vivências, curiosidades, promovam iniciativas, enfim, estratégias que colaborem para o desenvolvimento da autonomia [...]". (MORAES; TORRE, 2004, p.47).

A proposta de estágio transdisciplinar reafirmou os fundamentos e estratégias essenciais para reencantar a educação (MORAES; TORRE, 2004) e que é possível exercer uma docência pautada no rigor científico sem desconsiderar a sensibilidade, os sentimentos, as emoções, a alegria, o prazer de ensinar e de aprender. 


\section{Algumas considerações}

A discussão apresentada aqui deixa clara a urgência da busca de religar as diferentes dimensões da vida e as diferentes dimensões constitutivas do ser humano que foram fragmentadas pelo paradigma tradicional. A visão dicotomizada do paradigma tradicional determinou, em grande parte, concepções e práticas no campo da educação gerando uma visão fragmentada do conhecimento, das atitudes de ensinar e aprender, das ações e reações frente ao que a pessoa é ao que a pessoa faz e como ela conhece.

A hegemonia deste paradigma fez obscurecer outras formas de pensar, sentir e agir; fez desacreditar alternativas, experiências, conhecimentos que não fossem certificados pela ciência.

Esta proposta do Estágio transdisciplinar vem contrapor essa lógica fragmentária e excludente, sinalizando a possibilidade de efetivar práticas educativas que rompam com este paradigma por meio de fundamentos teórico-práticos do pensamento complexo e do paradigma emergente a nível, não do discurso, mas de ações concretas.

O estágio curricular supervisionado visou promover práxis complexa e transdisciplinar e mobilizar o sujeito para rever seu estilo de pensamento, suas concepções e sua relação com o outro, com o meio ambiente e consigo mesmo. Por construir um modo de pensar problematizado, relacional, que busca religar conhecimentos em perspectiva multidimensional e multirreferencial, busca-se coletivamente construir diálogos, ações, relações e mediações pedagógicas com potencial transformador de si mesmo, do social, da relação homem-natureza-sociedade e dos processos educativoformativos.

Os projetos transdisciplinares propostos e desenvolvidos no estágio rompeu com a lógica e os limites da disciplinaridade, dos exercícios de memória e dos conhecimentos acabados. Possibilitou aos alunos dos campos e os acadêmicos, condições de adquirir, investigar e refletir temas emergentes, e por meio de um pensamento complexo, religar conhecimentos e desenvolver ações e práticas transformadoras.

Essa reconfiguração na formação docente exigiu empreender a busca de um novo paradigma que leve em consideração as relações, as conexões e as interações entre ciência, consciência, homem, natureza e sociedade. A perspectiva de mudança e inovação carece entre outras coisas de uma reforma do pensamento (MORIN, 1999) e a abertura para perceber outras possibilidades além do que está posto pelo paradigma dominante. 
Os processos experimentados no Estágio Curricular Supervisionado nos anos iniciais do ensino fundamental na Escola João Lobo Filho possibilitaram que os estagiários (as) pudessem apreender, por meio de Projetos de Trabalho Transdisciplinares (HERNÁNDEZ; VENTURA, 1998), pensar complexo metatemas essenciais da atualidade que dizem respeito a própria preservação da vida como um todo no Planeta, bem como contribuiu para religar saberes e conhecimentos de modo ampliado e dinâmico, via experiências coletivas-reflexivas e autorais.

\section{Referências}

ALMEIDA, C. R. S. de. É possível exercer uma prática educativa baseada no pensamento complexo? In: MORAES, M. C.; SUANNO, J. H. (orgs.). O pensar complexo na educação. Rio de Janeiro: Walk Editora, 2014.

FAZENDA, I. Integração e interdisciplinaridade no ensino brasileiro: efetividade ou ideologia. São Paulo: Loyola, 1979.

HERNÁNDEZ, F.; VENTURA, M. A organização do currículo por projetos de trabalho. 5.ed. Porto Alegre: Artmed, 1998.

JAPIASSÚ, H. Interdisciplinaridade e patologia do saber. Rio de Janeiro: Imago, 1974.

MORAES, M. C. O paradigma educacional emergente. Campinas: Papirus, 1997.

MORAES, M. C.; TORRE, S. de la. Sentipensar: fundamentos e estratégias para reencantar a educação. Petrópolis -RJ: Vozes, 2004.

MORAES, M. C. Pressupostos teóricos do sentipensar. In: MORAES, M. C.; TORRE, S. de la. Sentipensar: fundamentos e estratégias para reencantar a educação. Petrópolis -RJ: Vozes, 2004.

MORAES, M. C. Ecologia dos saberes: complexidade, transdisciplinaridade e educação - novos fundamentos para iluminar novas práticas educacionais. São Paulo: Antakarana/WHH - Willis Harman House, 2008.

MORAES, M. C. Educação e sustentabilidade: um olhar complexo e transdisciplinar. 
In: MORAES, M. C.; SUANNO, J. H. (Orgs). O pensar complexo na educação- sustentabilidade, transdisciplinaridade e criatividade. Rio de Janeiro: Walk, Editora, 2014.

MORAES, M. C. Transdisciplinaridade, criatividade e educação. Fundamentos ontológicos e epistemológicos. Colaboração de Juan Miguel Batalloso Navas. Coleção Práxis. Campinas, SP: Papirus, 2015.

MORIN, E. A noção de sujeito. In: SCHNITMAN, D. F. (Org.). Novos paradigmas, cultura e subjetividade. Trad. Jussara Haubert Rodrigues. Porto Alegre: Artes Médicas, 1996.

MORIN, E. Por uma reforma do pensamento. In: PENA, A.; NASCIMENTO, E. P. O pensar complexo de Edgar Morin e a crise da modernidade. Rio de Janeiro: Garamond, 1999.

MORIN, E. Os sete saberes necessários à educação do futuro. Tradução de Catarina Eleonora F. da Silva \& Jeanne Sawaya. Revisão técnica de Edgard de Assis Carvalho. 2. ed. São Paulo: Cortez; Brasília, DF: UNESCO, 2000.

MORIN, E. Introdução ao Pensamento Complexo. Tradução Eliane Lisboa. 3.ed. Porto Alegre: Sulinas, 2007.

MORIN, E. Ciência com consciência. Rio de Janeiro: Bertrand Brasil, 2008.

MORIN, E. Sobre la reforma de la universidad. A Gazeta de Antropologia. Tradução José Luis Solana Ruiz. № 25 /1, 2009.

MORIN, E. La Vía. Para el futuro de la humanidade. Tradução Núria Petit Fontseré. Barcelona: Paidós, 2011.

NAVARRA, J. M. I. Ecoformação e Transdisciplinaridade: fundamentos para elaboração de um currículo do século XX em uma didática humanista. SUANNO, Marilza Vanessa Rosa; RAJADELL, Núria Puiggròs (Org.). Didática e formação de professores: perspectivas e inovações. Goiânia: CEPED Publicações e PUC Goiás, 2012. ISBN 97885-64604-03. 
NICOLESCU, B. O Manifesto da transdisciplinaridade. São Paulo: Triom, 1999.

PINEAU, G. Transdisciplinaridade, histórias de vidas, alternância. Articles et chapitres publiés em portugais (2000-2006). Document de recherche $n^{\circ} 18$. Departement des Science I’Éducation et de La Formation. Tours: Université François-Rabelais, 2006.

SANTOS, L. P. Um projeto, uma feira e muita aprendizagem... In: I Seminário da Rede Internacional de Escolas Criativas, 2014, Goiânia. Anais do I Seminário da Rede Internacional de Escolas Criativas. Goiânia: UEG/ UFG/RIEC, 2014. v.01. p.909 - 917.

SANTOS, L. P.; SUANNO, M. V. R. Escola sustentável e Feira de Ciências: reflexões e ações em torno da fabricação de sabão artesanal. In: PINHO, Maria José de; SUANNO, MarilzaVanessa Rosa; SUANNO, João Henrique (orgs). Projetos criativos na prática pedagógica: cantar e encantar a aprendizagem. Goiânia: Editora Espaço Acadêmico, 2015.

SUANNO, M. R. (coord.). Projetos, práticas e estágio nos anos iniciais do ensino fundamental- Ano Internacional de Cooperação pela água. Publicação da Escola Estadual em Tempo Integral João Lobo Filho. Inhumas, Goiás, 2013.

SUANNO, M. V. R.; SANTOS, L. P. Essa é uma história de uma feira de ciências... In: VI Fórum Internacional de Innovación y Creatividade: Escuelas y aulas Creativas, 2014, Barcelona. Escuelas y aulas creativas: reflexiones y experiencias. Barcelona: Institut de Ciències de I’Educació Universitat de Barcelona., 2014. v.01. p.151 - 166.

SUANNO, M. V. R. Estágio transdisciplinar na formação de professores. In: SILVA, V. L. de S. ; SCHROEDER, E. (orgs). Novos Talentos - processos educativos em ecoformação. Blumenau: Editora Legere, 2014.

SUANNO, M. (et al). Cidades sustentáveis e escolas sustentáveis. DESAFIOS, Revista da Universidade Federal de Tocantins - V.1, n.01, p. 186 - 206, jul/dez, 2014, entre outras.

SUANNO, M. V. R., MELO, K. A.; SANTOS, L. P. (et al). Projeto integrador inter/transdisciplinar: dimensões sustentáveis na formação do pedagogo e na parceria com as escolas campo de estágio. In: PINHO, Maria José de; SUANNO, MarilzaVanessa Rosa; SUANNO, João Henrique; FERRAZ, Elzimar Pereira Nascimento (orgs). Complexida- 
de, interdisciplinaridade e transdisciplinaridade na educação superior. Goiânia: Editora Espaço Acadêmico, 2015.

SUANNO, M. V. R. Estágio supervisionado com indícios transdisciplinares na formação de professores. PINHO, M. J.; SUANNO, M. V. R.; SUANNO, J. H.; FERRAZ, E. P. $\mathrm{N}$. Complexidade, interdisciplinaridade e transdisciplinaridade na educação superior. Goiânia: Espaço Acadêmico, 2015e.

SUANNO, M. V. R. S. Didática e trabalho docente sob a ótica do pensamento complexo e da transdisciplinaridade. 2015. 493 p. Tese de Doutorado em Educação, pelo Programa de Pós-Graduação Stricto Sensu em Educação, pela Universidade Católica de Brasília - UCB, Brasília-DF, 2015d.

Recebido em: 16 abril 2016.

Aceito em: 28 abril 2016. 